\title{
Application of Groundwater Model to Groundwater Regulation in Cangzhou Area
}

\author{
Juyan Zhu ${ }^{1}$, Yunlong Wang ${ }^{1}$, Haipeng Guo ${ }^{1, *}$, Xisheng Zang ${ }^{1}$, and Tongchun Qin ${ }^{1}$ \\ ${ }^{1}$ China Institute of Geological Environment Monitoring, Beijing, China
}

\begin{abstract}
The development and utilization of groundwater in Cangzhou area has led to a series of environmental and geological problems such as groundwater-level declines and land subsidence. In order to alleviate the impact of groundwater abstraction on geological environment, a calibrated, transient groundwater numerical model of the Cangzhou area was developed using Processing Modflow. Then four kinds of groundwater exploitation schemes were designed and the groundwater flow fields for different schemes in the next 50 years were simulated and predicted. By comparing and analyzing the variation of the water levels in the mining layers and the variation of groundwater storage, the optimal groundwater extraction scheme was determined.
\end{abstract}

\section{Introduction}

Water resource is one of the most basic conditions for human survival and development. The problem of water resource shortage is attracting more and more attentions. How to make sustainable use of limited freshwater resources is a focus of our work. Due to the surface water resources are insufficient and heavily polluted, the exploitation and utilization of groundwater occupy an increasing proportion in the water structure [1]. It is known to all that the North China plain has serious groundwater overdraft, and has the largest groundwater funnel area. According to statistics, overexploitation of groundwater in the north China plain has led to the decrease of water levels by $1 \mathrm{~m}$ per year in the shallow aquifer systems and by $5 \mathrm{~m}$ per year in the deep aquifer systems [2]. Cangzhou, located in the middle-east of the North China plain, is the most typical area with groundwater overdraft.

As the beginning of the quantitative understanding of the movement of groundwater, Henry Darcy, a French engineer in 1856, proposed Darcy's formula based on the sand trough experiment. Since then, the groundwater computing technology has gone through the analytical research stage, physical simulation method stage and computer numerical simulation stage [3-4]. In recent decades, the numerical simulation technology has made great progress. Theoretically, for any complex groundwater problem, the response accuracy can be obtained by using the numerical method [5].

MODFLOW is commonly used groundwater simulation software in the world, which can carry out distributed simulation of water flow in different underground aquifer units and easily connect with other models [6]. In this paper, the simulation of aquifer system in Cangzhou is carried out through the Processing Modflow. Based on the groundwater model, this paper analyzes the groundwater exploitation schemes and groundwater flow fields in Cangzhou area in the next 50 years, and obtains the best groundwater exploitation scheme at last.

\section{The groundwater model in Cangzhou area}

The simulation area for this study includes the Quaternary loose sediments in the whole Cangzhou area (Fig.1), with an area of about $1.43 \times 10^{4} \mathrm{~km}^{2}$. According to the characteristics of quaternary aquifer group, the entire Quaternary stratum is divided into 8 strata groups. Clay layers are interbedded with sand soil layers. The clay layer is weak permeable layer and the sand soil layer is aquifer.

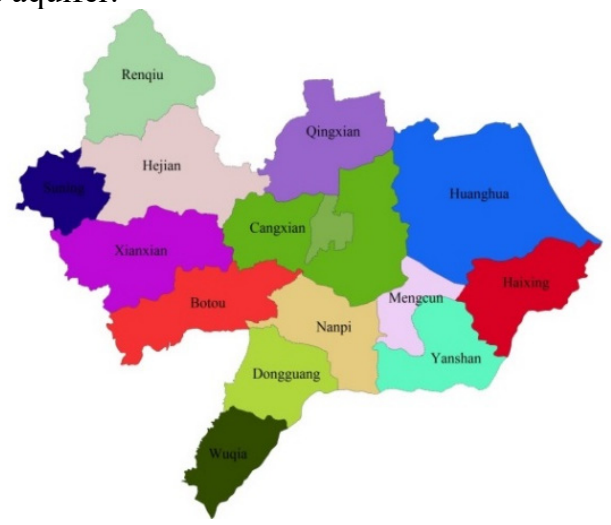

Fig. 1. Schematic diagram of the scope of the research area

${ }^{*}$ Corresponding author: Haipeng Guo: guohp@mail.cigem.gov.cn 
Model discretization includes horizontal grid discretization and vertical grid discretization grid discretization. Horizontally, the study area was subdivided into 164 rows and 191 columns based on equidistant partition of $1 \mathrm{~km} \times 1 \mathrm{~km}$. Vertically, the Quaternary strata of the study area was divided into 8 layers, of which the bottom depths are: $10-15 \mathrm{~m}, 20-30 \mathrm{~m}$, 70-100 m, 120-170 m, 185-260 m, 250-350 m, 300-450 $\mathrm{m}, 350-550 \mathrm{~m}$, respectively. Totally, this model was discretized into 164 (row) $\times 191$ (column) $\times 8$ (layer), with a total of 250592 grids. Among which, in accordance with the division of the administrative boundary, the grids outside Cangzhou were set inactive.

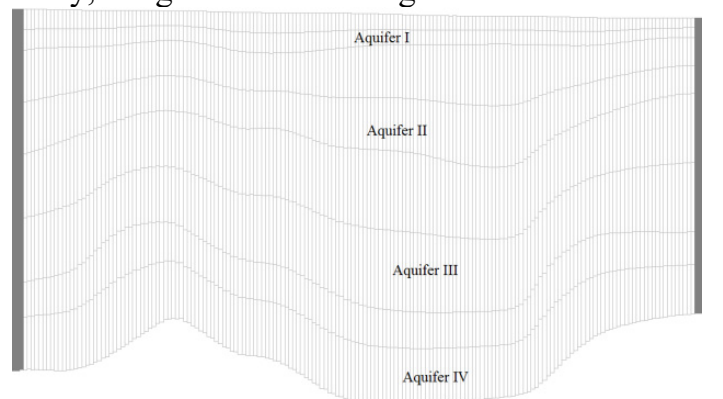

Fig. 2. Vertical subdivision of the model

The east side of the study area, the Bohai Sea, is natural boundary, of which the sea level change is small. Therefore, the eastern boundary was set as the constant water head boundary, with the water head of $0 \mathrm{~m}$. The data in 2006 was selected for the simulation period, and the data from January, 2007 to December, 2010 were selected for the testing period, and the stress period was set to be a month.

According to the hydrogeological conditions in the study area, hydraulic conductivities of the four aquifers were divided into 63 zones. The order of magnitude of the hydraulic conductivity for the aquitard is $10^{-5}-10^{-2}$ $\mathrm{m} / \mathrm{d}$ and that of the specific storage is $10^{-7}-10^{-5} \mathrm{~m}^{-1}$. Precipitation recharge coefficient zoning was based on the district administrative boundaries.

In model testing period (January, 2007 - December, 2010), according to the fitting result of simulated and measured groundwater flow fields of aquifer III in December, 2010 (Fig. 3), we can see that the calculated and measured distributions of groundwater flow fields and the locations of cones of depression are generally consistent.

During the model simulation, a total of 32 observation wells were set for fitting the simulated and observed groundwater levels, which basically controlled the whole simulation region. By comparing the simulated and measured water levels, the errors in simulation period are within the allowable range (Fig. 4).

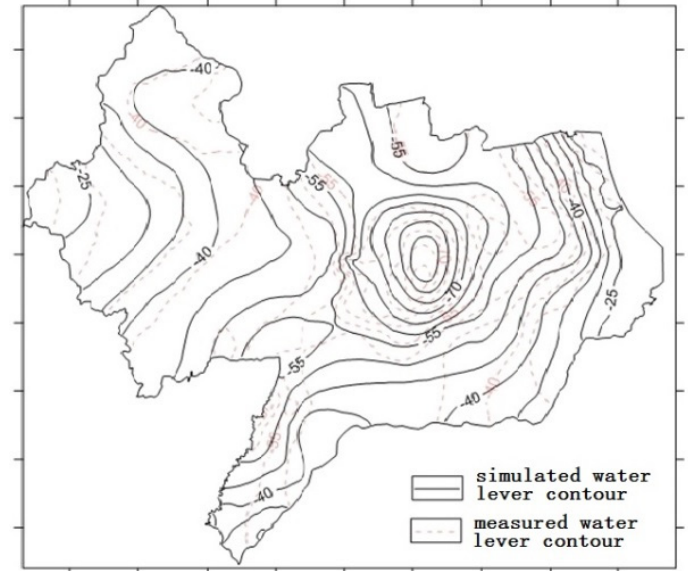

Fig. 3. Fitting figure of the groundwater flow field of aquifer III in December, 2010

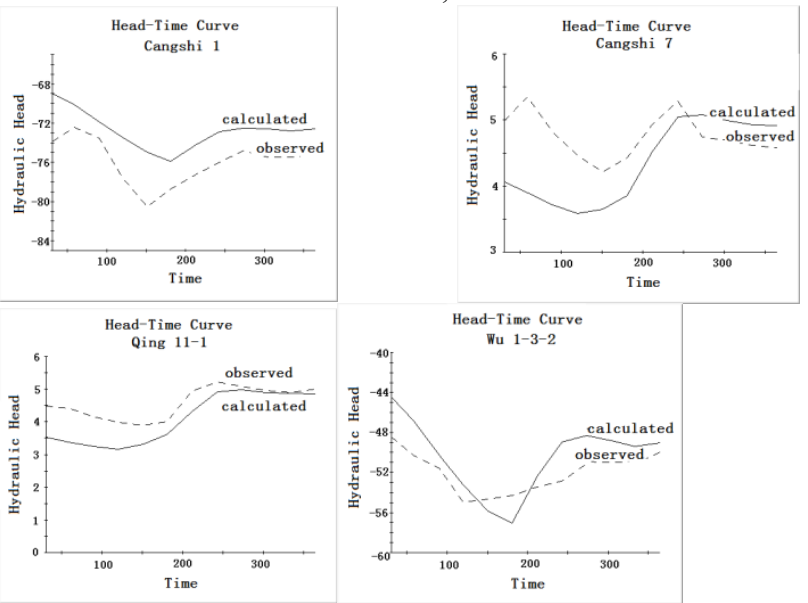

Fig. 4. Water level fitting figure of some observation wells

To sum up, both the flow fields and the water levels are generally consistent between the measured and calculated values, indicating that the constructed three-dimensional groundwater flow model in this study for hydrogeological condition generalization, identification of hydrogeological parameters, and description of boundary condition, is basically in accordance with the actual situation. Therefore, the results of the model simulation are reliable, which can be used to predict the dynamic change of groundwater levels in the future.

\section{Analysis of Groundwater abstraction schemes of Cangzhou Area}

Table 1. Description of four exploiting schemes

\begin{tabular}{|c|l|}
\hline $\begin{array}{c}\text { Exploiting } \\
\text { schemes }\end{array}$ & \multicolumn{1}{c|}{ Features } \\
\hline $\begin{array}{c}\text { Current } \\
\text { Exploitation } \\
\text { (case1) }\end{array}$ & $\begin{array}{l}\text { Using the average recharge and } \\
\text { discharge items of 2006-2010 as the } \\
\text { new recharge and discharge items }\end{array}$ \\
\hline & $\begin{array}{l}\text { To shut down the exploiting wells in } \\
\text { urban area; to shut down the exploiting } \\
\text { wells where the accumulated } \\
\text { settlement over 1000 mm; to reduce } \\
\text { the exploiting wells in the subsidence } \\
\text { areas and the new groundwater } \\
\text { depression cones. A total pumping } \\
\text { amount of 3.07 } \times 10^{8} \mathrm{~m}^{3} / \text { a will be } \\
\text { reduced under Restricted Exploitation. }\end{array}$ \\
$\begin{array}{c}\text { Restricted } \\
\text { Exploitation } 2)\end{array}$ \\
\begin{tabular}{c} 
Adding injection wells along the \\
\hline Water
\end{tabular}
\end{tabular}




\begin{tabular}{|c|l|}
\hline $\begin{array}{c}\text { Exploiting } \\
\text { schemes }\end{array}$ & \multicolumn{1}{c|}{ Features } \\
\hline $\begin{array}{c}\text { Injection } \\
\text { Project } \\
\text { (case3) }\end{array}$ & $\begin{array}{l}\text { Beijing-Shanghai high-speed railway; } \\
\text { adding injection wells in urban area; } \\
\text { adding injection wells in subsidence } \\
\text { area and new groundwater depression } \\
\text { cones. Under Water Injection Project, } \\
\text { a total amount of } 2.96 \times 10^{8} \mathrm{~m}^{3} / \mathrm{a} \text { of } \\
\text { artificial recharge will be injected. }\end{array}$ \\
\hline $\begin{array}{l}\text { Combining Restricted Exploitation and } \\
\text { Water Injection Project, to seek the } \\
\text { optimum scheme for sustainable } \\
\text { groundwater exploitation. Under this } \\
\text { scheme, the reducing amount of } \\
\text { exploitation will be } 1.54 \times 10^{8} \mathrm{~m}^{3} / \mathrm{a}, \\
\text { and the injection amount will be } 1.48 \times \\
\text { Scheme } \\
\text { (case4) }\end{array}$ \\
$10^{8} \mathrm{~m}^{3} / \mathrm{a}$.
\end{tabular}

With the help of the constructed numerical model, the groundwater regime of Cangzhou area was analyzed for the next fifty years under four different exploiting schemes. (Table 1). Under the Current Exploitation condition (case1), the location of the original center of the depression cone remains unchanged, and the groundwater levels in the depression cone will decline slightly. Due to the constant exploitation in western area, large area of depression cones will occur and the deepest groundwater level will be $-118.8 \mathrm{~m}$.

By Restricted Exploitation (case2), the water levels of aquifer III will increase slightly compared to case1. The water level of the original subsidence center of Cangxian will be $-72 \mathrm{~m}$. Due to the reduction of groundwater exploitation in the western area, water levels will slightly rise, and the shallowest water level is $-81 \mathrm{~m}$.

For Water Injection Project (case3), the locations of depression cones will change in accordance with the distribution of injection wells. Water levels in urban area will rise significantly, while those in the western area will decrease continuously. The deeptest water level will be $-91 \mathrm{~m}$, and the water level of the original subsidence center will rise up to $-39 \mathrm{~m}$.

Due to restriction and suspension of exploitation and water injection (Case4), water level drops in western area will be alleviated, while water levels in the urban area will rise greatly. The lowest water level in western area will be $-83 \mathrm{~m}$, while the highest water level in urban area will rise up to $-24 \mathrm{~m}$.

The average annual storage variation under four exploitation schemes is shown on Table 2 and Fig. 5.

Table 2. Statistics of storage variation under different exploitation schemes unit: $10^{8} \mathrm{~m}^{3}$

\begin{tabular}{|c|c|}
\hline Exploitation schemes & $\begin{array}{c}\text { Average annual } \\
\text { storage variation }\end{array}$ \\
\hline Current Exploitation & -2.57 \\
\hline Restricted Exploitation & -0.46 \\
\hline Water Injection Project & -0.62 \\
\hline Combined Scheme & -0.55 \\
\hline
\end{tabular}

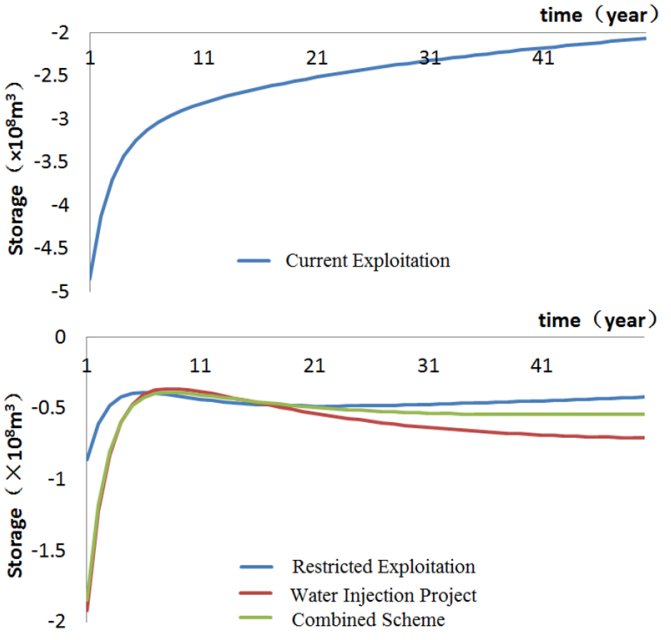

Fig. 5. Change curves of storage variation under four exploitation schemes

Known from the analysis of the above schemes for groundwater exploitation, under the current exploiting conditions, continuous drop of groundwater level is bound to consume the storage of aquifers, which will cause groundwater depletion and unable sustainable exploitation and utilization. In spite that the Restricted Exploitation and Water Injection Project and the Combined Scheme cannot make groundwater system reach stable state, or make the storage variation become zero, by the measures of these schemes, the groundwater levels in eastern Cangzhou and the original subsidence center can recover to a certain extent, and the storage variation will approach to zero. In a long term, groundwater system will reach to a stable state.

According to changes of water level and equilibrium analysis of different schemes, the Current Exploitation is infeasible, by which the water levels will continue to drop significantly, while the water levels will increase in different extents by the other schemes. Three observation wells (D1, D2 and D3) were set in different regions, and the water level variations for the proposed 4 schemes were shown in Fig.6.

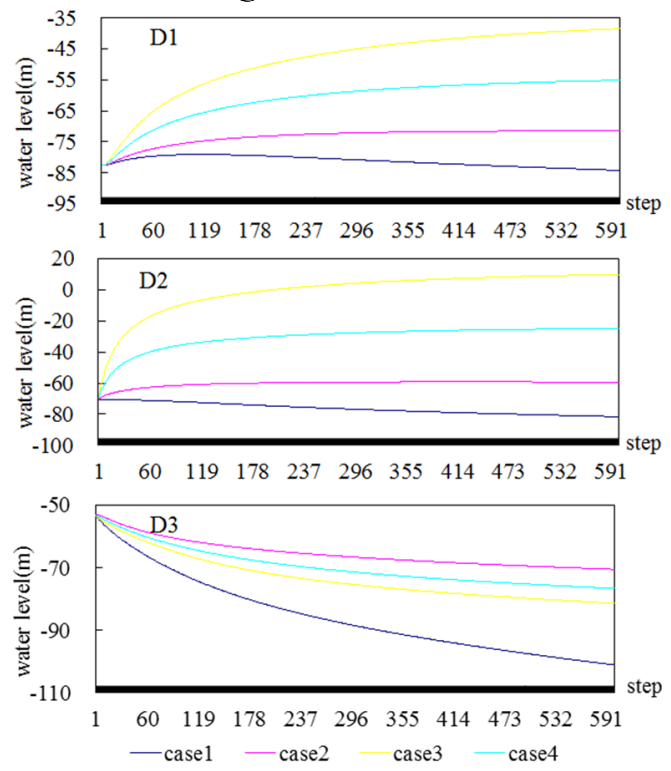

Fig. 6. Water level changes of the observation wells D1, D2 and D3 
From the water level change curves of different observation wells under the four schemes, it can be seen that water levels will continue to drop under case 1 and case2, of which water level will decrease slower under Restricted Exploitation. Water levels will increase in most areas under case 3 and case4, and eventually become steady. In order to satisfy the requirement of agricultural, industrial and living water usage, the exploitation amount keeps great in the western area so that water levels will not recover greatly. As can be seen from Fig.6, Restricted Exploitation, Water Injection Project and Combined Scheme can only slow down the water level drops in the western area, but cannot increase the water levels and make them stable.

By comparing the water level change curves of the four schemes, we can see that Combined Scheme has the advantages of both Restricted Exploitation and Water Injection Project, which can assure the demand of living and urban construction water usage, and also protect the groundwater resource in the whole area, as can be considered the optimum scheme for sustainable exploitation.

\section{Conclusions}

The groundwater model can simulate and predict the trend of groundwater level very well and plays a key role in the regulation of regional groundwater.

If groundwater extraction with long time series, the storage variation will eventually approach 0 and the groundwater level reaches a steady state. The integrated use of restricted exploitation and water injection project can not only effectively alleviate the decline of groundwater level, but also guarantee the domestic water demand and urban construction water demand.

\section{Recommendations}

In order to alleviate the groundwater overdraft in Cangzhou area, scientific and reseaonable groundwater development planning should put into practice according to the characteristics of this region. Much more efforts should be made to adopt resticion and suspenction of groundwater, increase recharge of the aquiers, and discover new water sources.

When development of groundwater resources causes subsidence, it is necessary for the governments to exercise their power either to prohibit the resource development or to control it in ways that minimize damage. However, the population and economic activities in Cangzhou area are heavily dependent upon the groundwater resource. Therefoere, it is important to seek a balance between controlling subsidence and assuring adequate water supply. This may be done through regulation. With adequate monitoring programs and institutional mechanisms in place, optimal benefits may be achieved for both resource development and subsidence allevation. To achieve goal, investigation, monitoring and controlling studies of land subsidence need to be strengthended, based on which some management countermeasures should be conducted for controlling land subsidence according to the land subsidence hazard zoning.

\section{Acknowledgements}

This work was supported by the projects: China Geological Survey (Grant No. DD20160235 , 12120115042501), and the National Natural Science Foundation of China (Grant No. 41877294).

\section{References}

1. Cheng M-X, Ma F-S. Groundwater Resources and the Environment in China, 470-476, (2002)

2. FosterS S D, et al. Hydrogeology Journal, 12(1):81 -93, (2004)

3. Bear J. Fluid Dynamics of Porous Media, (1983)

4. Xue Y-Q. Groundwater Hydraulics,

5. Wang h, etc. Geosci Front, 17 (6) : 1-12, (2010)

6. Zhu J-F, etc. China Environmental Science, 35 (9) : 2820-2826, (2015) 